\title{
Physical activity and cardiovascular risk factors in children
}

\author{
Lars Bo Andersen, ${ }^{1,2}$ Chris Riddoch, ${ }^{3}$ Susi Kriemler, ${ }^{4}$ Andrew Hills ${ }^{5}$
}

${ }^{1}$ Department of Exercise Epidemiology, Center for Research in Childhood Health, University of Southern

Denmark, Odense, Denmark

${ }^{2}$ Department of Sports

Medicine, Norwegian School

of Sport Sciences, Oslo,

Norway

${ }^{3}$ Department for Health, University of Bath, Bath, UK

${ }^{4}$ Swiss Tropical and Public

Health Institute, University of

Basel, Basel, Switzerland

${ }^{5}$ Griffith University and

Mater Medical Research

Institute (MMRI), Brisbane,

Queensland, Australia

\section{Correspondence to}

Lars Bo Andersen, Department

of Exercise Epidemiology,

Center for Research in

Childhood Health, University of

Southern Denmark, Campusvej

55, 5230 Odense M, Denmark;

lboandersen@health.sdu.dk

Accepted 20 June 2011

Published Online First

26 July 2011

\begin{abstract}
Background A number of recent systematic reviews have resulted in changes in international recommendations for children's participation in physical activity (PA) for health. The World Health Authority (WHO) has recently released new recommendations. The WHO still recommends 60 min of moderate to vigorous physical activity (MVPA), but also emphasises that these minutes should be on top of everyday physical activities. Everyday physical activities total around 30 min of MVPA in the quintile of the least active children, which means that the new recommendations constitute more activity in total compared with earlier recommendations.
\end{abstract}

Objective To summarise evidence justifying new PA recommendation for cardiovascular health in children.

Methods The results of recent systematic reviews are discussed and supplemented with relevant literature not included in these reviews. PubMed was searched for the years 2006-2011 for additional topics not sufficiently covered by the reviews.

Results PA was associated with lower blood pressure and a healthier lipid blood profile in children. The association was stronger when a composite risk factor score was analysed, and the associations between physical fitness and cardiovascular disease (CVD) risk factors were even stronger. Muscle strength and endurance exercise each had an effect on blood lipids and insulin sensitivity even if the effect was smaller for muscle strength than for aerobic exercise. New evidence suggests possible effects of PA on C-reactive protein.

Conclusion There is accumulating evidence that PA can have beneficial effects on the risk factors of CVD in children. Public health policy to promote PA in children, especially the most sedentary children, may be a key element to prevent the onset of CVD later in the children's lives.

\section{INTRODUCTION}

This overview includes a consideration of literature published since 2005 summarising associations between PA and cardiovascular disease (CVD) risk factors in children. In 2005, Strong et a ${ }^{1}$ published a comprehensive systematic review of the effects of physical activity (PA) on seven different health outcomes. The review identified 850 articles, which included CVD risk factors such as blood lipids, blood pressure and clustered CVD risk factors. A number of studies reporting associations with haemostatic factors and markers of inflammation were also included. Based on the review, Strong et al recommended that children should accumulate $60 \mathrm{~min}$ of moderate to vigorous (MVPA) every day. This recommendation was primarily based on a judgment of the amount of
PA included in different intervention studies. It is important to note that none of the intervention studies reported how active children were beside the intervention, and despite that recommendations included information regarding total MVPA. Moreover, few studies at that time had collected objective measures of PA.

Since this review, studies have been published where PA has been assessed objectively. Another improvement has been to analyse a composite score of CVD risk factors. These studies generally report stronger associations because CVD risk factors tend to cluster in sedentary and obese children. A further area of development has been studies analysing the association between PA and inflammatory markers.

Previous recommendations for PA in children have suggested a total of 60 min of MVPA per day. However, our knowledge of total PA levels of children has been limited, primarily because activity has been assessed by self report - a method known to carry unacceptable levels of error in terms of quantifying PA. The emergence of more precise, objective methods of assessing activity has greatly enhanced our understanding in this field. A further issue is that previous recommendations have been based primarily on the results of generally small intervention studies. However, interventions generally do not take the PA of daily living into account. They only quantify the activity added to everyday living. This may have caused an underestimation of the total PA necessary to maintain cardiovascular health.

A further review by Janssen and LeBlanc ${ }^{2}$ updated the literature on PA and health. However, due to the large number of studies in the area, they limited their search to studies that reported outcomes as dichotomous variables. Limiting studies in this way effectively excludes most of the more recent (and larger) studies that have used objective measures of PA, because these studies have often treated the outcome variables as continuous variables. We believe this to be a major limitation of this review for two reasons. First, the studies utilising the more precise measurements of PA have been omitted. Yet, their greater measurement precision probably gives their results greater validity and hence importance. Second, the process of dichotomising outcome variables reduces power and hence associations will tend to be weaker. Furthermore, most of the CVD risk factors show linear relationships with PA in adults.

The aim of this review is to summarise results from the previous reviews of Strong et a ${ }^{1}$ and Janssen $e t a l,{ }^{2}$ and to extend their findings with (1) studies relating objective measures of PA to 
CVD risk factors, ${ }^{3}$ (2) recent studies including inflammatory markers as outcomes and (3) studies analysing CVD risk using composite - or 'clustered' - CVD risk scores. ${ }^{4}$

\section{METHODS}

A PubMed search (2005-January 2011) was undertaken for publications in English related to PA and individual biological CVD risk factors in children (excluding obesity, which is reported in a separate article). PubMed was then searched to identify review articles. Additional articles were added from reviews and reference lists from other articles with special emphasis given to studies relating objective measures of PA to cardiovascular risk factors. Finally, a search was conducted to identify studies analysing composite risk factor scores for CVD risk factors.

\section{RESULTS}

\section{Blood pressure}

A meta-analysis from 2003 indicates no clear association between PA and blood pressure in normotensive children, ${ }^{5}$ while there are some indications that prolonged programs can lower blood pressure in hypertensive children. Some studies of children with systemic hypertension show a beneficial effect of aerobic activity programs of $12-32$ week duration on blood pressure, ${ }^{6-8}$ but an 8 -week strength training program by itself had no influence on blood pressure in hypertensive children. ${ }^{910}$ The lack of effect of exercise on blood pressure in this study may be related to the short duration of the training intervention, because interventions with longer duration do find a gradual increase in effect. ${ }^{8}$ Strength training after an aerobic activity intervention has been shown to prevent the return of blood pressure to preintervention levels in hypertensive adolescents. ${ }^{11} 12$

Observational studies have found a dose-response association between aerobic fitness and blood pressure, ${ }^{13} 14$ but these studies found no association between self-reported sports participation and blood pressure. The inverse association between aerobic fitness and blood pressure was stronger in overweight children. ${ }^{14}$ Associations between aerobic fitness and hypertension were moderate in magnitude with ORs for hypertension of 1.5-3.0 for the least fit. In the study of Nielsen and Andersen, ${ }^{14}$ risk was only elevated in the lowest quintile of fitness, but in the study of Andersen, ${ }^{13}$ an inverse, graded association between fitness and blood pressure was observed from a fitness level below 50 and $45 \mathrm{ml} / \mathrm{min} / \mathrm{kg}$ in boys and girls, respectively.

Experimental studies have almost entirely focused on children with hypertension 671112 or obesity, 81516 and most studies had small sample sizes. The two largest studies included $99^{6}$ and 67 children, respectively. ${ }^{8}$ Hansen et al studied both normotensive and hypertensive overweight children. They observed a reduction in systolic and diastolic blood pressures in the training subgroups of 6.5 and $4.1 \mathrm{~mm} \mathrm{Hg}$, respectively, in the normotensive group, and 4.9 and $3.8 \mathrm{~mm} \mathrm{Hg}$, respectively, in the hypertensive group, after 8 months of training. Most intervention studies have included between 60 and 180 min/week of prescribed exercise. This equates to 9-30 min/day when averaged over a week. Overall, the results from these intervention studies were positive with reports of significant reductions in systolic blood pressure in response to aerobic exercise training, with effect sizes in excess of $0.80 .^{6-811} 1215-17$ Three of the interventions including aerobic training also reported significant reductions $(\sim 6-11 \%)$ in diastolic blood pressure. ${ }^{811} 15$ Studies that used training modalities other than aerobic exercise, such as muscular resistance exercise, were less conclusive with small to modest effect sizes being observed. ${ }^{2}$

In conclusion, these data suggest that a PA/exercise intervention with a duration of at least $30 \mathrm{~min}$, a frequency of 3 times/week and intensity sufficient to improve aerobic fitness can be effective in reducing blood pressure in children with hypertension.

\section{Blood lipids}

In observational studies, associations between PA and total cholesterol, high-density lipoprotein cholesterol (HDL-C), low-density lipoprotein cholesterol (LDL-C) and triglyceride levels are generally weak. ${ }^{18}$ Nevertheless, associations suggest an overall beneficial effect of PA on HDL-C and triglyceride levels, but no consistent effect on total cholesterol or LDL-C levels. ${ }^{1}$

Dobbins et a ${ }^{19}$ published a Cochrane review in 2009 including seven school-based randomised controlled trials (RCTs) that included a measure of lipids as outcome measure in response to a PA intervention. This review identified seven studies. ${ }^{20-26}$ Two further studies have been published since this review. ${ }^{27} 28$ Overall, studies including clinical or school-based trials (randomised and non-randomised) show a weak beneficial effect on HDL-C and triglyceride levels, but no effect on total cholesterol or LDL-C levels. ${ }^{29-31}$ School-based interventions have generally not been effective in improving lipid and lipoprotein levels, but many of these interventions have also failed to increase PA or fitness. ${ }^{24} 32$ In a recent 2-year schoolbased intervention, which did increase physical fitness, beneficial effects were also found on triglyceride (13\% decrease) and the ratio of total:HDL cholesterol (6\% decrease). ${ }^{27}$ Similar beneficial changes in blood lipids were observed in a Swiss school-based intervention. ${ }^{28}$ Beneficial effects are usually seen when the intervention is substantive enough to change aerobic fitness. ${ }^{33}$

The review of Janssen and LeBlanc ${ }^{2}$ was limited to studies with dichotomous outcomes. As discussed earlier, most observational studies report linear associations rather than risk of hypercholesterolaemia. This is in contrast to blood pressure, where the existence of hypertension as a dichotomised variable is commonly used. Some of the observational studies contradict findings of the intervention studies that commonly report that HDL rather than total cholesterol is associated with PA or fitness. Data from the European Youth Heart Study suggest weak but highly significant associations between objectively measured PA and total cholesterol and triglyceride, but no association with HDL. ${ }^{18}$ In the same project, triglyceride and $\mathrm{HDL}$ have also been reported to be associated with indicators of muscle fitness such as handgrip strength, situps, muscular endurance and a composite score of these tests. ${ }^{34}$

Intervention studies conducted outside school tend to only include children with hypercholesterolaemia or obesity. Janssen and LeBlanc ${ }^{2}$ included six RCTs and two nonrandomised interventions. Results from these studies are mixed. The five studies that were based on aerobic exercise alone observed significant improvements in at least one lipid/ lipoprotein variable. The interventions that were based on resistance training ${ }^{35}$ and circuit training ${ }^{15}$ reported small and/ or insignificant changes for all of the lipid/lipoprotein variables examined, and the effect sizes within these studies tended to be quite small.

It appears that a minimum of 40 min of moderate activity per day, 5 days per week for at least 4 months is required to 
achieve improvement in lipid and lipoprotein levels, primarily increased HDL-C and decreased triglyceride levels. ${ }^{1}$ This implies the need for a sustained amount of MVPA on a regular basis in order to induce and maintain a beneficial effect. Observational studies indicate a graded association between amount of PA and blood lipid levels.

\section{Clustered CVD risk}

Metabolic syndrome (MetS) was first described in adults, but retrospective evaluation of paediatric data suggests that MetS characteristics exist in 3-14\% of the general population of children and in $13-37 \%$ of obese children. ${ }^{36}$ Clustering of CVD risk factors is based on the fact that CVD risk factors are not independently distributed in the population but cluster in some individuals. Although there appears to be consensus regarding the risk factors for MetS in adults, there is no consensus for the definition in children and adolescents. The reason for the lack of consensus lies in the fact that children do not routinely exhibit CVD; thus, it is difficult to relate the criteria to a health outcome. The condition is therefore defined as clustered CVD risk by some authors, while others still use MetS, even if definitions differ between authors. In addition, in early stages of insulin resistance, fasting blood glucose is not elevated, because the resistance is compensated by a large increase in insulin production. Fasting glucose is therefore a problematic component of the MetS in children. A number of suggestions for defining cutoff points for MetS in children have been published. ${ }^{37-39}$ Alternatively, composite scores based on the sum of percentile ranking and sum of sex- and age-specific z-scores have also been used. ${ }^{18}$ 40-42 The different CVD risk factors usually included in the definitions are waist circumference (or BMI), triglycerides, blood pressure, fasting glucose and reduced HDL-C level. It would make sense to include physical fitness as part of the score, as it is difficult to find a rationale for including measures of fatness but not fitness, considering that both these conditions are strongly associated with clustering of other CVD risk factors such as insulin resistance, blood lipids and blood pressure.

Studies relating self-reported PA to MetS are inconclusive. Pan and Pratt ${ }^{43}$ used the PA section of the NHANES 1999-2002 questionnaire and found no significant relationship between PA and MetS in 4450 adolescents aged 12-19 years. Andersen et $a^{44}$ also reported no association between self-reported PA and MetS in 305 children participating in the Danish Youth and Sport Study. Conversely, Moore et al, ${ }^{45}$ using the Youth Risk Behavior Surveillance, found that those children reporting low PA had three times the risk of MetS compared with children with high PA levels. McMurray et al ${ }^{46}$, also using a validated questionnaire, found that children who developed MetS as adolescents had 22\% lower PA scores than those children who did not develop MetS. Kelishadi et al, ${ }^{47}$ also using a PA questionnaire in 4811 adolescents aged 6-18 years, found a small difference in the overall rate of MetS between tertiles of PA. Children with low PA levels were 1.6-1.8 times more likely to have MetS. In the review of Janssen and LeBlanc, ${ }^{2}$ the summary OR for the least active group relative to the most active group was 1.68 for self-reported PA (95\% CI: 1.22 to 2.31).

The findings of a relationship between PA and MetS have been more consistent when accelerometry was used to estimate PA. Brage et al ${ }^{48}$ determined the relationship between accelerometer-measured PA and MetS z-score in 389 Danish children. They found a graded negative association between PA levels and MetS z-score. A study of 529 Swedish children aged 9 and 15 years also found an inverse relationship between
PA and MetS, particularly in 15-year-old girls. ${ }^{49}$ They suggested that the relationship was strongest because the 15-yearold girls had the lowest levels of PA. Other studies from the European Youth Heart Study measured PA levels with accelerometry in 1730-2800 children aged 9 and 15 years and used a z-score classification for MetS. ${ }^{18} 41$ They found a graded association in MetS z-score through all PA percentiles. Of note, accelerometry data suggested that MVPA had to be about 90 $\mathrm{min} /$ day to effectively reduce the risk of MetS.

Rizzo et al $^{49}$ analysed a composite CVD risk factor score against quartiles of fitness and found strong associations in both boys and girls. Further examination of these later studies revealed a clear dose-response relation. A recent follow-up of Copenhagen Schoolchild Intervention Study by Andersen et al showed that the association between fitness and MetS became much stronger in the same children from 6 to 9 years of age. The OR between upper and lower quintiles increased from 2 to 35 in this age span, and metabolic syndrome seemed to develop after the age of 6 years. Janssen and LeBlanc reported four studies that used direct measures of cardiorespiratory fitness. $^{2} 42445051$ All reported strong and significant relations with MetS. The summary OR for the least fit group relative to the most fit group in the four studies that measured fitness was 6.79 (95\% CI: 5.11 to 9.03). Several studies show improvement in elements of the MetS in association with PA in obese and non-obese children, ${ }^{15} 3552-55$ but the amount of activity necessary to prevent or treat the MetS is not specified.

\section{CVD risk factors and muscle fitness}

Few studies have examined the association of the muscular endurance and strength with CVD risk factors among children and adolescents. ${ }^{56-58}$ Two of these studies included measurement of maximal strength only, and the associations are only analysed with individual CVD risk factors and not clustered metabolic risk. ${ }^{56} 58$ García-Artero et al ${ }^{57}$ measured muscle endurance, explosive strength and maximal strength and included a lipid-metabolic risk score in their analyses. However, they did not directly measure cardiorespiratory fitness, and they could therefore not analyse whether there was an association independent of aerobic fitness. Only one study has evaluated the association of both single and combined muscle strength measurements with MetS risk independent of aerobic fitness. ${ }^{34}$ In this study, muscle fitness was negatively associated with clustered metabolic risk, independent of cardiorespiratory fitness, but the association was weaker than for cardiorespiratory fitness.

\section{Other cardiovascular variables}

Thomas and Williams and Thomas et al have conducted two comprehensive reviews of studies of the effect of exercise on C-reactive protein (CRP), interleukin 6 (IL-6) and fibrinogen. 5960 CRP is an acute-phase reactant that increases significantly in response to trauma and inflammation. CRP is a sensitive marker of inflammation, and there is evidence of its causal role in inflammation. ${ }^{61}$ Age, sex, body mass index, adiposity, physical inactivity, physical fitness and smoking are associated with CRP levels. ${ }^{62}$ There is evidence to suggest that regular PA protects against disease associated with chronic low-grade systemic inflammation and decrease the level of CRP. ${ }^{63}$ The mechanisms responsible for the association between reduced CRP and increased PA are unknown, partly because PA is related to several confounders that are independently associated with CRP concentration. Many researchers claim that PA mainly 
affects health through its relation to fatness. However, if PA causes changes in fat tissue, which produces cytokines affecting CRP, PA remains the primary cause of the change.

Studies reporting the association between PA and CRP concentration in young people are relatively scant, with much of the research concentrating on overweight and obese individuals. ${ }^{59}$

Observational studies have shown associations between PA and CRP. ${ }^{64} 65$ Other studies using self-reported PA have failed to find an association with CRP. ${ }^{66-69}$ When physical fitness is analysed, studies find much stronger associations to CRP. Andersen et al found an association between cardiorespiratory fitness and CRP of -0.49 in 9 -year-old children. They further found an 11.3 times higher risk for CVD risk factors to cluster in the upper quartile of CRP compared with the lower quartile. The reason why PA shows a weaker association with CRP than fitness could be that only high-intensity aerobic exercise may have an effect. Alternatively, it could be the fact that PA is assessed with higher levels of error.

Most intervention studies only include obese children, and many of them have small sample size. Interventions including PA or PA and diet lasting 4-6 months have found reduction in CRP in obese adolescents. ${ }^{557071}$ Change in CRP was independent of weight. Conversely, Nassis et al ${ }^{72}$ found no reduction in CRP in a study of obese girls although cardiorespiratory fitness increased by $18.8 \%$. Lack of effect on CRP was also found in two studies of obese children by Barbeau et a l $^{73}$ and Kelly et $a l^{74}$ but the latter study only included nine subjects, and the small sample size may have caused a statistical type 2 error.

The role of exercise on other inflammatory markers is controversial. Hotamisligil et a ${ }^{75}$ observed that adipose tissue from obese mice was producing tumour necrosis factor $\alpha(\mathrm{TNF} \alpha)$, a proinflammatory marker, and this cytokine was responsible for insulin resistance. This observation changed our view on adipose tissue, and it has become apparent that obesity is linked to a state of chronic inflammation. Obesity results not only in the secretion of TNF $\alpha$, but induces the release of many cytokines including resistin, IL-1 and IL- 6 . Given this proinflammatory response and the observation that systemic IL- 6 concentrations are elevated in obesity, it is generally thought that elevations in IL- 6 have a negative effect on metabolism. ${ }^{76}$ However, it is now proven that muscle cells also act as an endocrine organ, and among other substances produce IL- 6 during contraction. ${ }^{77}$ Myokines, which are cytokines produced by the muscle cells, may be involved in mediating the health beneficial effects of exercise and play important roles in the protection against diseases associated with low-grade inflammation, insulin resistance, hyperlipidaemia such as CVDs, type 2 diabetes and cancer. IL- 6 produced by the muscle enhances glucose uptake in the muscle cells, glucose production from the liver and lipolysis in the adipose tissue. Training studies have shown that adaptation to training reduces IL- 6 response in plasma. However, even if plasma-IL- 6 appears to be downregulated by training, the muscular expression of the IL- 6 receptor appears to be upregulated. ${ }^{77}$ How these observations apply to children is not known. Furthermore, it is difficult to evaluate the role of IL- 6 in observational studies, because the acute response to exercise disappears fast, and fasting blood samples may therefore not be suitable. ${ }^{78}$ Most intervention studies are conducted in obese children. A decrease in IL- 6 has been found in obese children after an exercise intervention, ${ }^{70}$ but it has also been seen in normal weight children. ${ }^{71}$ Currently, there is no consensus of the effect of PA on inflammation in children.

\section{Cardiovascular fitness (aerobic fitness)}

Correlational studies indicate low-to-moderate positive relationships between PA and both maximal and submaximal indicators of aerobic fitness. The strength of the association depends on how accurately PA and to some degree aerobic fitness are assessed. Dencker and Andersen $^{3}$ reviewed studies using objectively measured PA in children. The objective data from these studies strongly suggest that the amount of PA in childhood is weakly associated with aerobic fitness with $r$ values of $0.25-0.40$.

Experimental training studies with children aged 8 years and older indicate improvements in aerobic fitness. ${ }^{24} 28303279-81$ Some intervention studies have used high-intensity aerobic sports, but it is interesting that differences in fitness were also found in relation to everyday activities such as cycling to school, and the differences seem not to be caused by selection. ${ }^{82-85}$ Programs involving continuous vigorous activity for $>30 \mathrm{~min}$ at least 3 days per week result in an approximately $10 \%$ increase in fitness ( $3-4 \mathrm{ml} / \mathrm{kg} / \mathrm{min}$ ). However, cycling to school, which is a PA repeated twice a day, results in $8-9 \%$ change in aerobic fitness.

\section{DISCUSSION}

PA recommendations in relation to metabolic health in children have changed since the first recommendation was formulated by the American College of Sports Medicine in 1988. ${ }^{86}$ PA was focused on aerobic exercise performed at an intensity sufficient to increase aerobic fitness. This has gradually changed, and emphasis is now placed on both aerobic and resistance exercise. The change in recommendations is based on the evidence of an independent association between muscle fitness and metabolic disorders. Another change was related to the quantity of recommended exercise. Since the recommendations published in the late 1990s by Biddle et al, ${ }^{87}$ most authorities have recommended 60 min of at least moderate-intensity PA accumulated most days as the main goal. WHO's latest Global Guidelines recommend that $60 \mathrm{~min}$ of at least moderate intensity should be accumulated on top of activities of daily living. ${ }^{88}$ Studies using accelerometry have shown that even the most sedentary children accumulate to around 30-40 min of MVPA per day. ${ }^{18}$ This change is therefore a major increase in recommended PA level in children. The change is logical, because earlier evidence was based primarily on intervention studies and self-reported PA in observational studies. Intervention studies describe the content of the intervention, but there is usually no knowledge of what PA participants participated in outside the intervention. Two factors have increased our understanding in this area. These are a better quantification of PA by accelerometry and a more accurate definition of metabolic outcomes. The introduction of a composite CVD risk factor score based on continuous z-scores has improved associations between exposure and outcome, which makes it possible to better quantify the amount and type of PA children need to improve health.

Development of methods to assess PA objectively can still be improved. There is still no consensus on how to assess PA in children and adolescents reliably regarding the appropriate time period representative for overall PA and the inflation factor that should be used to account for the behavioural variation of PA in youth. Other limitations of accelerometry are related to the lack of ability to quantify cycling and swimming. These limitations may soon be overcome, because much research is focused on combining different measures such as accelerometry, heart rate, cycle computers and global positioning 
system. Metabolic outcome measures can also be improved. Dichotomisation of metabolic variables has mainly been used to help physicians decide when drug treatment was justified, but treatment of children with metabolic disorders will probably mainly be based on lifestyle changes in the future except for children having specific genetic problems such as familiar hypercholesterolaemia. Therefore, it makes sense to use continuous scores to define metabolic health. Despite all these limitations, we believe that the current 2010 WHO recommendation is based on solid evidence.

\section{Competing interests None.}

Provenance and peer review Not commissioned; externally peer reviewed.

\section{REFERENCES}

1. Strong WB, Malina RM, Blimkie CJ, et al. Evidence based physical activity for school-age youth. J Pediatr 2005;146:732-7.

2. Janssen I, LeBlanc AG. Systematic review of the health benefits of physical activity and fitness in school-aged children and youth. Int J Behav Nutr Phys Act 2010;7:40.

3. Dencker M, Andersen LB. Health-related aspects of objectively measured daily physical activity in children. Clin Physiol Funct Imaging 2008;28:133-44.

4. McMurray RG, Andersen LB. The influence of exercise on the metabolic syndrome in youth: a review. Am J Lifestyle Med 2010;4: 176-86.

5. Kelley GA, Kelley KS, Tran ZV. The effects of exercise on resting blood pressure in children and adolescents: a meta-analysis of randomized controlled trials. Prev Cardiol 2003;6:8-16

6. Ewart CK, Young DR, Hagberg JM. Effects of school-based aerobic exercise on blood pressure in adolescent girls at risk for hypertension. Am J Public Health 1998;88:949-51.

7. Danforth JS, Allen KD, Fitterling JM, et al. Exercise as a treatment for hypertension in low-socioeconomic-status black children. J Consult Clin Psychol 1990; 58:237-9.

8. Hansen HS, Froberg K, Hyldebrandt N, et al. A controlled study of eight months of physical training and reduction of blood pressure in children: the Odense schoolchild study. BMJ 1991;303:682-5.

9. Laird WP, Fixler DE, Huffines FD. Cardiovascular response to isometric exercise in normal adolescents. Circulation 1979;59:651-4.

10. Fixler DE, Laird WP, Browne R, et al. Response of hypertensive adolescents to dynamic and isometric exercise stress. Pediatrics 1979;64:579-83.

11. Hagberg JM, Goldring D, Ehsani AA, et al. Effect of exercise training on the blood pressure and hemodynamic features of hypertensive adolescents. Am J Cardiol 1983;52:763-8.

12. Hagberg JMM, Ehsani AA, Goldring D, et al. Effect of weight training on blood pressure and hemodynamics in hypertensive adolescents. J Pediatr 1984;104:147-51.

13. Andersen LB. Blood pressure, physical fitness and physical activity in 17-yearold Danish adolescents. J Intern Med 1994;236:323-9.

14. Nielsen GA, Andersen LB. The association between high blood pressure, physical fitness, and body mass index in adolescents. Prev Med 2003;36:229-34

15. Bell LM, Watts K, Siafarikas A, et al. Exercise alone reduces insulin resistance in obese children independently of changes in body composition. J Clin Endocrinol Metab 2007;92:4230-5.

16. Kahle EB, Zipf WB, Lamb DR, et al. Association between mild, routine exercise and improved insulin dynamics and glucose control in obese adolescents. Int J Sports Med 1996;17:1-6.

17. Jago R, Jonker ML, Missaghian M, et al. Effect of 4 weeks of Pilates on the body composition of young girls. Prev Med 2006;42:177-80.

18. Andersen LB, Harro M, Sardinha LB, et al. Physical activity and clustered cardiovascular risk in children: a cross-sectional study (The European Youth Heart Study). Lancet 2006;368:299-304.

19. Dobbins M, De Corby K, Robeson P, et al. School-based physical activity programs for promoting physical activity and fitness in children and adolescents aged 6-18. Cochrane Database Syst Rev 2009;1:CD007651.

20. Alexandrov A, Isakova G, Maslennikova G, et al. Prevention of atherosclerosis among 11-year-old schoolchildren in two Moscow administrative districts. Health Psychol 1988;7(Suppl):247-52.

21. Walter HJ, Hofman A, Vaughan RD, et al. Modification of risk factors for coronary heart disease. Five-year results of a school-based intervention trial. N Engl J Med 1988;318:1093-100

22. Bush PJ, Zuckerman AE, Taggart VS, et al. Cardiovascular risk factor prevention in black school children: the "Know Your Body" evaluation project. Health Educ 0 1989;16:215-27.

23. Lionis C, Kafatos A, Vlachonikolis J, et al. The effects of a health education intervention program among Cretan adolescents. Prev Med 1991;20:685-99.
24. Luepker RV, Perry CL, McKinlay SM, et al. Outcomes of a field trial to improve children's dietary patterns and physical activity. The Child and Adolescent Trial for Cardiovascular Health. CATCH collaborative group. JAMA 1996;275:768-76.

25. Manios Y, Moschandreas J, Hatzis C, et al. Evaluation of a health and nutrition education program in primary school children of Crete over a three-year period. Prev Med 1999;28:149-59.

26. Bayne-Smith M, Fardy PS, Azzollini A, et al. Improvements in heart health behaviors and reduction in coronary artery disease risk factors in urban teenaged girls through a school-based intervention: the PATH program. Am J Public Health 2004;94:1538-43.

27. Resaland GK, Anderssen SA, Holme I, et al. Effects of a 2-year school-based daily physical activity intervention on cardiovascular disease risk factors: the Sogndal school-intervention study. Scand J Med Sci Sports 2010;(In Press).

28. Kriemler S, Zahner L, Schindler C, et al. Effect of school based physical activity programme (KISS) on fitness and adiposity in primary schoolchildren: cluster randomised controlled trial. BMJ 2010;340:c785.

29. Eliakim A, Makowski GS, Brasel JA, et al. Adiposity, lipid levels, and brief endurance training in nonobese adolescent males. Int J Sports Med 2000;21:332-7.

30. Stoedefalke K, Armstrong N, Kirby BJ, et al. Effect of training on peak oxygen uptake and blood lipids in 13 to 14 -year-old girls. Acta Paediatr 2000;89:1290-4

31. Cohen CJ, McMillan CS, Samuelson DR. Long-term effects of a lifestyle modification exercise program on the fitness of sedentary, obese children. J Sports Med Phys Fitness 1991;31:183-8.

32. Donnelly JE, Jacobsen DJ, Whatley JE, et al. Nutrition and physical activity program to attenuate obesity and promote physical and metabolic fitness in elementary school children. Obes Res 1996;4:229-43.

33. Reed KE, Warburton DE, Macdonald HM, et al. Action Schools! BC: a schoolbased physical activity intervention designed to decrease cardiovascular disease risk factors in children. Prev Med 2008;46:525-31.

34. Steene-Johannessen J, Anderssen SA, Kolle E, et al. Low muscle fitness is associated with metabolic risk in youth. Med Sci Sports Exerc 2009;41:1361-7.

35. Lau PWC, Yu CW, Lee A, et al. The physiological and psychological effects of resistance training on Chinese obese adolescents. J Exerc Sci Phys Fitness 2004:2:115-20.

36. de Ferranti SD, Gauvreau K, Ludwig DS, et al. Prevalence of the metabolic syndrome in American adolescents: findings from the Third National Health and Nutrition Examination Survey. Circulation 2004;110:2494-7.

37. Weiss R, Dziura J, Burgert TS, et al. Obesity and the metabolic syndrome in children and adolescents. N Engl J Med 2004;350:2362-74.

38. Jolliffe CJ, Janssen I. Development of age-specific adolescent metabolic syndrome criteria that are linked to the Adult Treatment Panel III and International Diabetes Federation criteria. J Am Coll Cardiol 2007;49:891-8.

39. Ford ES, Ajani UA, Mokdad AH. The metabolic syndrome and concentrations of C-reactive protein among U.S. youth. Diabetes Care 2005;28:878-81.

40. Andersen LB, Haraldsdóttir J. Tracking of cardiovascular disease risk factors including maximal oxygen uptake and physical activity from late teenage to adulthood. An 8-year follow-up study. J Intern Med 1993;234:309-15.

41. Andersen LB, Sardinha LB, Froberg K, et al. Fitness, fatness and clustering of cardiovascular risk factors in children from Denmark, Estonia and Portugal: the European Youth Heart Study. Int J Pediatr Obes 2008;3(Suppl 1):58-66.

42. Anderssen SA, Cooper AR, Riddoch C, et al. Low cardiorespiratory fitness is a strong predictor for clustering of cardiovascular disease risk factors in children independent of country, age and sex. Eur J Cardiovasc Prev Rehabil 2007:14:526-31.

43. Pan Y, Pratt CA. Metabolic syndrome and its association with diet and physical activity in US adolescents. J Am Diet Assoc 2008;108:276-86; discussion 286

44. Andersen LB, Hasselstrøm H, Grønfeldt V, et al. The relationship between physical fitness and clustered risk, and tracking of clustered risk from adolescence to young adulthood: eight years follow-up in the Danish Youth and Sport Study. Int J Behav Nutr Phys Act 2004;1:6.

45. Moore JB, Davis CL, Baxter SD, et al. Physical activity, metabolic syndrome, and overweight in rural youth. J Rural Health 2008;24:136-42.

46. McMurray RG, Bangdiwala SI, Harrell JS, et al. Adolescents with metabolic syndrome have a history of low aerobic fitness and physical activity levels. Dyn Med 2008; 7:5.

47. Kelishadi R, Razaghi EM, Gouya MM, et al. Association of physical activity and the metabolic syndrome in children and adolescents: CASPIAN Study. Horm Res 2007; 67:46-52.

48. Brage S, Wedderkopp N, Ekelund U, et al. Features of the metabolic syndrome are associated with objectively measured physical activity and fitness in Danish children: the European Youth Heart Study (EYHS). Diabetes Care 2004; 27:2141-8.

49. Rizzo NS, Ruiz JR, Hurtig-Wennlöf A, et al. Relationship of physical activity, fitness, and fatness with clustered metabolic risk in children and adolescents: the European youth heart study. J Pediatr 2007;150:388-94. 
50. Carnethon MR, Gulati M, Greenland P. Prevalence and cardiovascular disease correlates of low cardiorespiratory fitness in adolescents and adults. JAMA 2005;294:2981-8

51. Hansen SE, Hasselstrøm H, Grønfeldt V, et al. Cardiovascular disease risk factors in 6-7-year-old Danish children: the Copenhagen School Child Intervention Study. Prev Med 2005:40:740-6.

52. Stergioulas A, Tripolitsioti A, Messinis D, et al. The effects of endurance training on selected coronary risk factors in children. Acta Paediatr 1998;87:401-4.

53. Ferguson MA, Gutin B, Le NA, et al. Effects of exercise training and its cessation on components of the insulin resistance syndrome in obese children. Int J Obes Relat Metab Disord 1999;23:889-95

54. Heyman E, Toutain C, Delamarche $\mathrm{P}$, et al. Exercise training and cardiovascular risk factors in type 1 diabetic adolescent girls. Pediatr Exerc Sci 2007;19:408-19.

55. Meyer AA, Kundt G, Lenschow U, et al. Improvement of early vascular changes and cardiovascular risk factors in obese children after a six-month exercise program. J Am Coll Cardiol 2006;48:1865-70.

56. Benson AC, Torode ME, Fiatarone Singh MA. A rationale and method for highintensity progressive resistance training with children and adolescents. Contemp Clin Trials 2007;28:442-50.

57. García-Artero E, Ortega FB, Ruiz JR, et al. [Lipid and metabolic profiles in adolescents are affected more by physical fitness than physical activity (AVENA study)]. Rev Esp Cardiol 2007;60:581-8.

58. Janz KF, Dawson JD, Mahoney LT. Increases in physical fitness during childhood improve cardiovascular health during adolescence: the Muscatine Study. Int J Sports Med 2002;23 Suppl 1:S15-21.

59. Thomas NE, Williams DR. Inflammatory factors, physical activity, and physical fitness in young people. Scand J Med Sci Sports 2008;18:543-56.

60. Thomas NE, Baker JS, Davies B. Established and recently identified coronary heart disease risk factors in young people: the influence of physical activity and physical fitness. Sports Med 2003;33:633-50.

61. Pasceri V, Willerson JT, Yeh ET. Direct proinflammatory effect of C-reactive protein on human endothelial cells. Circulation 2000;102:2165-8.

62. Abramson JL, Vaccarino V. Relationship between physical activity and inflammation among apparently healthy middle-aged and older US adults. Arch Intern Med 2002;162:1286-92.

63. Plaisance EP, Grandjean PW. Physical activity and high-sensitivity C-reactive protein. Sports Med 2006;36:443-58.

64. Syrenicz A, Garanty-Bogacka B, Syrenicz M, et al. Relation of low-grade inflammation and endothelial activation to blood pressure in obese children and adolescents. Neuro Endocrinol Lett 2006;27:459-64.

65. Cook DG, Mendall MA, Whincup PH, et al. C-reactive protein concentration in children: relationship to adiposity and other cardiovascular risk factors. Atherosclerosis 2000;149:139-50.

66. Platat C, Wagner A, Klumpp T, et al. Relationships of physical activity with metabolic syndrome features and low-grade inflammation in adolescents. Diabetologia 2006;49:2078-85

67. Thomas NE, Baker JS, Graham MR, et al. C-reactive protein in schoolchildren and its relation to adiposity, physical activity, aerobic fitness and habitual diet. Br J Sports Med 2008;42:357-60.

68. Moran A, Steffen LM, Jacobs DR Jr, et al. Relation of C-reactive protein to insulin resistance and cardiovascular risk factors in youth. Diabetes Care 2005:28:1763-8.
69. Ischander M, Zaldivar F Jr, Eliakim A, et al. Physical activity, growth, and inflammatory mediators in BMI-matched female adolescents.

Med Sci Sports Exerc 2007;39:1131-8.

70. Balagopal P, George D, Patton N, et al. Lifestyle-only intervention attenuates the inflammatory state associated with obesity: a randomized controlled study in adolescents. J Pediatr 2005;146:342-8.

71. Rosenbaum M, Nonas C, Weil R, et al. School-based intervention acutely improves insulin sensitivity and decreases inflammatory markers and body fatness in junior high school students. J Clin Endocrinol Metab 2007;92:504-8.

72. Nassis GP, Papantakou K, Skenderi K, et al. Aerobic exercise training improves insulin sensitivity without changes in body weight, body fat, adiponectin, and inflammatory markers in overweight and obese girls. Metab Clin Exp 2005;54:1472-9.

73. Barbeau P, Litaker MS, Woods KF, et al. Hemostatic and inflammatory markers in obese youths: effects of exercise and adiposity. J Pediatr 2002;141:415-20.

74. Kelly AS, Steinberger J, Olson TP, et al. In the absence of weight loss, exercise training does not improve adipokines or oxidative stress in overweight children. Metab Clin Exp 2007;56:1005-9.

75. Hotamisligil GS, Shargill NS, Spiegelman BM. Adipose expression of tumor necrosis factor-alpha: direct role in obesity-linked insulin resistance. Science 1993;259:87-91.

76. Lazar MA. How obesity causes diabetes: not a tall tale. Science 2005;307:373-5.

77. Pedersen BK, Febbraio MA. Muscle as an endocrine organ: focus on musclederived interleukin-6. Physiol Rev 2008;88:1379-406.

78. Andersen LB, Müller K, Eiberg S, et al. Cytokines and clustered cardiovascular risk factors in children. Metab Clin Exp 2010;59:561-6

79. Eliakim A, Scheett T, Allmendinger N, et al. Training, muscle volume, and energy expenditure in nonobese American girls. J Appl Physiol 2001;90:35-44.

80. Tolfrey K, Campbell IG, Batterham AM. Aerobic trainability of prepubertal boys and girls. Ped Exerc Sci 1998;10:248-63.

81. Resaland GK, Andersen LB, Mamen A, et al. Effects of a 2-year school-based daily physical activity intervention on cardiorespiratory fitness: the Sogndal school-intervention study. Scand J Med Sci Sports 2011;21:302-9.

82. Cooper AR, Wedderkopp N, Wang H, et al. Active travel to school and cardiovascular fitness in Danish children and adolescents. Med Sci Sports Exerc 2006;38:1724-31.

83. Andersen LB, Wedderkopp N, Kristensen PL, et al. Cycling to school and cardiovascular risk factors. A longitudinal study. J Phys Act Health 2010; (In Press)

84. Cooper AR, Wedderkopp N, Jago R, et al. Longitudinal associations of cycling to school with adolescent fitness. Prev Med 2008:47:324-8.

85. Andersen LB, Lawlor DA, Cooper AR, et al. Physical fitness in relation to transport to school in adolescents: the Danish youth and sports study. Scand J Med Sci Sports 2009;19:406-11.

86. ACSM. Physical fitness in children and youth. Med Sci Sports Exerc 1988;20:422-3.

87. Biddle S, Sallis JF, Cavill N. Young and active. Health Education Authority, London;1999:1-167.

88. WHO. Global Recommendations on Physical Activity for Health. Switzerland WHO, 2010 
BJSM

Physical activity and cardiovascular risk factors in children

Lars Bo Andersen, Chris Riddoch, Susi Kriemler, et al.

Br J Sports Med 2011 45: 871-876 originally published online July 26, 2011

doi: 10.1136/bjsports-2011-090333

Updated information and services can be found at:

http://bjsm.bmj.com/content/45/11/871.full.html

These include:

References This article cites 83 articles, 24 of which can be accessed free at: http://bjsm.bmj.com/content/45/11/871.full.html\#ref-list-1

Email alerting Receive free email alerts when new articles cite this article. Sign up in service the box at the top right corner of the online article.

Notes

To request permissions go to:

http://group.bmj.com/group/rights-licensing/permissions

To order reprints go to:

http://journals.bmj.com/cgi/reprintform

To subscribe to BMJ go to:

http://group.bmj.com/subscribe/ 